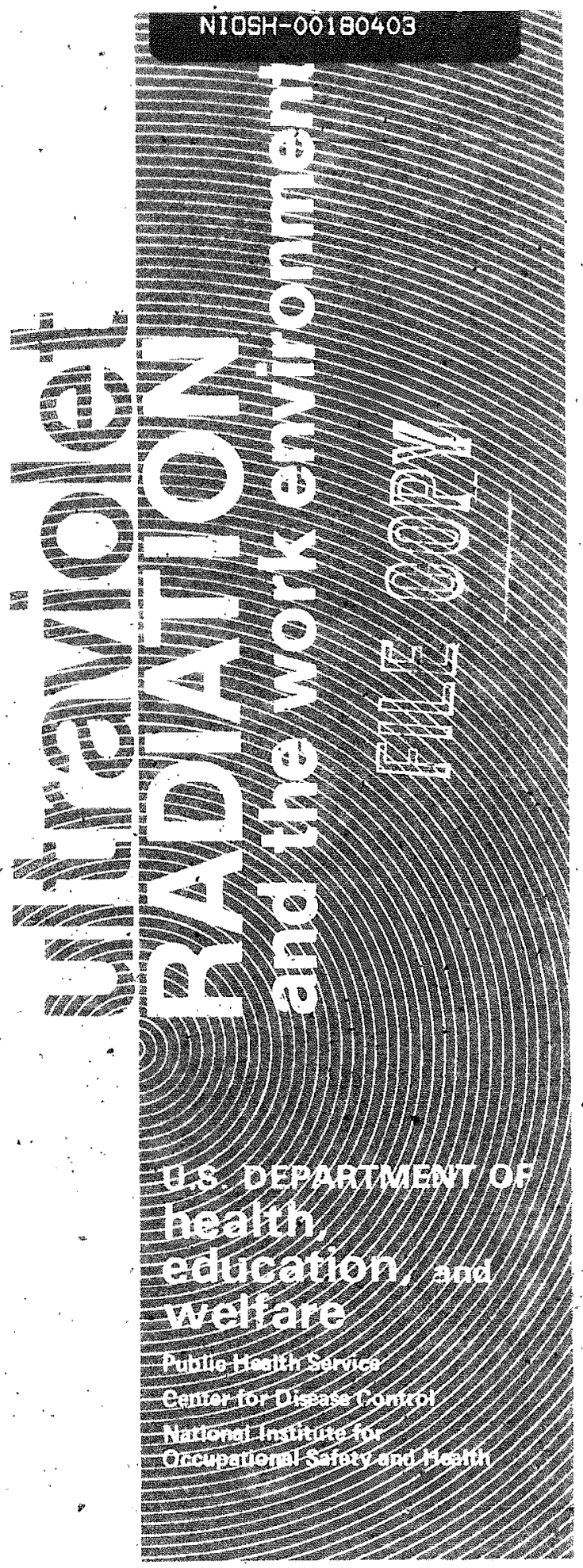




\section{ULTRAVIOLET RADIATION AND THE WORK ENVIRONMENT}

Ultraviolet radiation is an invisible radiant energy that is produced by natural and artificial sources and accompanies much visible light. It makes fluorescent lamps light, instrument panel dials glow, and special effects appear in visual presentation. It is used also in chemical synthesis and analysis, product inspection, crime detection, medical diagnosis and treatment, photoengraving, photocopying, photo-electric scanning, and electrostatic processes.

The sun is the major natural source of ultraviolet radiation. Many artificial sources are found on the industrial scene, such as germicidal lamps, carbon arcs, welding and cutting torches, furnaces, and laboratory test and analysis equipment.

\section{How Ultraviolet Radiation Can Harm You}

Ultraviolet radiation can be injurious to the skin and particularly to the eyes. We are all familiar with skin damage as sunburn, which is caused by ultraviolet radiation that is part of the sun's light. How bad the sunburn is depends on the length of exposure and the intensity of the radiation, as well as on the individual's sensitivity. Continued exposure to ultraviolet radiation speeds skin aging and can even cause skin cancer, a condition most common among people who must wor': in the sun a lot, such as farmers, seamen, and power line workers.

Exposure of the eyes to ultraviolet radiation is particularly dangerous because the radiation cannot be seen or, at first, felt. Consequently, an individual being exposed is not always aware that his eyes are being affected. The invisible radiation may later produce discomfort due to its absorption by the outer layer of the eye. Conjunctivitis, the resulting condition (often called "ground glass eyeball" or "welder's flash"), usu- ally occurs four to eight hours after exposure. It is extremely painful and, although usually temporary, can cause permanent injury to the eyes.

\section{Controlling Exposure}

Ultraviolet radiation is so readily absorbed by the human skin and eye that the exposure often is severe and becomes so painful that the worker quickly learns to protect himself thereafter. Prolonged exposure of the unprotected skin and eyes to ultraviolet radiation should always be avoided and persons with fair skin, especially, should avoid even occasional exposure. Barrier creams and lotions give some protection for brief expos. ures; however, protective clothing, gloves, and face shields are advised for all exposures, whether brief, intermittent, or prolonged. Enclosures or shields that are nontransparent to the radiation also can be used to control the exposure to radiation.

Approved goggles, properly fitted with appropriate lenses, are essential for all welding, cutting, and open-arc operations. Side and back screens should be used for these operations to protect nearby workmen. Remember that bright shiny surfaces can reflect harmful ultraviolet light from an open arc and should be masked or removed from the work areas.

\section{Providing Ventilation}

Ventilation is not needed to protect the worker's skin or eves from radiation, but to remove toxic gases that may be created by the interaction of ultraviolet radiation with air and atmospheric contaminants. This interaction can produce hazardous concentrations of ozone, oxides of nitrogen, and other toxic gases. These toxic gases can be produced by the interaction of solvent vapors and ultraviolet radiation (or, for that matter, by contact of the gases with arcs or hot metal surfaces). For these reasons it is essential that workplaces where ultraviolet radiation is present be well ventilated, bearing in mind that photochem- 


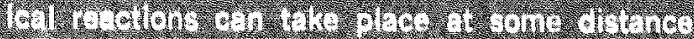

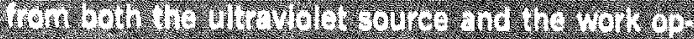

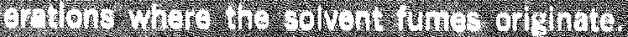

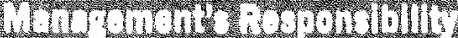

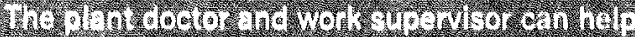

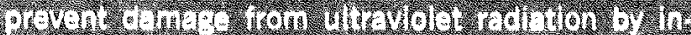

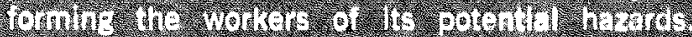

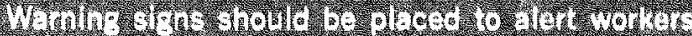

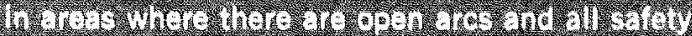

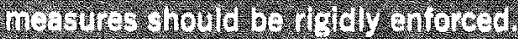

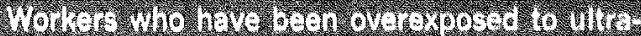

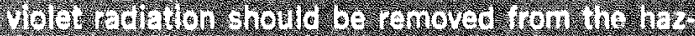

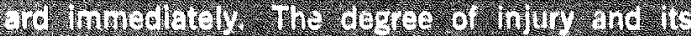

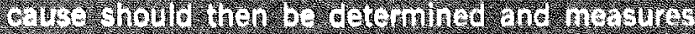

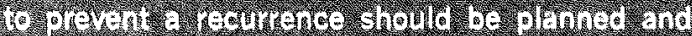
Divistor infert

\section{Whor sivoluthom}

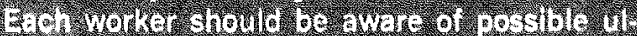

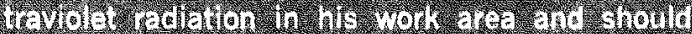

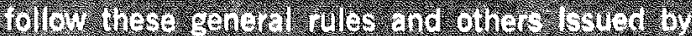

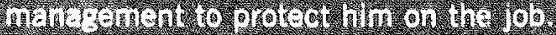

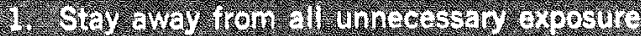

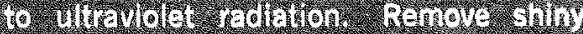

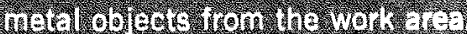

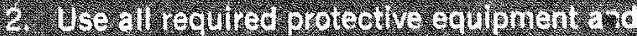

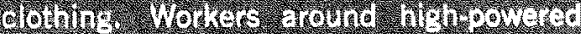

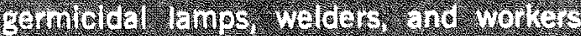

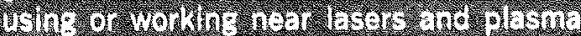

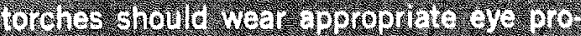
tadetion

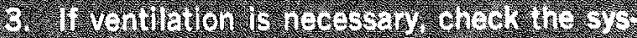

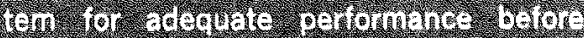

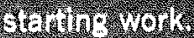

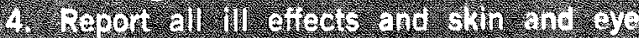

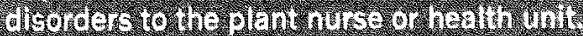

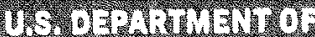

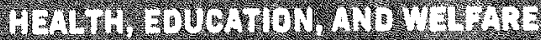

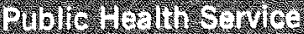

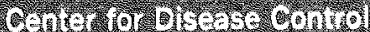

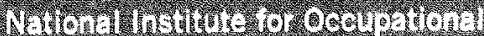

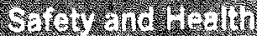

1478

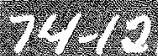

